\title{
Severe combined cardiac and neuromuscular toxicity from immune checkpoint blockade: an institutional case series
}

Puja Arora ${ }^{1 \dagger}$, Laura Talamo ${ }^{2 \dagger}$, Patrick Dillon ${ }^{3}$, Ryan D. Gentzler ${ }^{3}$, Trish Millard ${ }^{3}$, Michael Salerno ${ }^{4}$, Craig L. Slingluff $\mathrm{Jr}^{5}$ and Elizabeth M. Gaughan ${ }^{3^{*}}$ (i)

\begin{abstract}
Background: Immune checkpoint inhibition is part of standard systemic management for many advanced malignancies. Toxicities from this treatment approach are unpredictable, though usually reversible with management per established guidelines. Some patients suffer major morbidity and treatment-related mortality from these agents in an unpredictable manner. Cardiac and neurologic complications are rare, but can result in serious clinical consequences.

Methods: We describe the presentation, management, and outcomes of eight sequential cases of combined cardiac and neurologic toxicities resulting in severe illness and demonstrating lack of rapid response to immunosuppression.
\end{abstract}

Results: Our cohort consisted of six males and two females with an average age of 73.5 years (61-89years). There were four patients with melanoma, and one patient each with urothelial carcinoma, renal cell carcinoma, breast cancer, and non-small cell lung cancer. Four patients received combination immunotherapy and four patients received monotherapy. The median time to presentation from treatment initiation was 27 days (11-132 days). All patients had a cardiovascular and neurologic toxicity, and most had hepatitis and myositis. The cardiac signs and symptoms were the prominent initial features of the clinical presentation. Each patient was managed by a multidisciplinary team and received a range of immunosuppressive agents. All patients died as a consequence of the immune related adverse events.

Conclusions: The evaluation of patients with cardiac adverse events from immunotherapy, should include assessment of overlapping toxicities such as myasthenia gravis and myositis. Providers should be aware of the potential for an extended duration of disability and slow improvement for certain toxicities as these expectations may factor prominently in goals of care decisions.

Keywords: Combination immunotherapy, Immune related adverse events, Myocarditis, Myasthenia gravis, Myositis

\footnotetext{
* Correspondence: egaughan@virginia.edu

${ }^{\dagger}$ Puja Arora and Laura Talamo contributed equally to this work.

${ }^{3}$ Department of Medicine, Division of Hematology and Medical Oncology,

University of Virginia, PO Box 800716, Charlottesville, VA 22908, USA

Full list of author information is available at the end of the article
}

(c) The Author(s). 2020 Open Access This article is licensed under a Creative Commons Attribution 4.0 International License, which permits use, sharing, adaptation, distribution and reproduction in any medium or format, as long as you give appropriate credit to the original author(s) and the source, provide a link to the Creative Commons licence, and indicate if changes were made. The images or other third party material in this article are included in the article's Creative Commons licence, unless indicated otherwise in a credit line to the material. If material is not included in the article's Creative Commons licence and your intended use is not permitted by statutory regulation or exceeds the permitted use, you will need to obtain permission directly from the copyright holder. To view a copy of this licence, visit http://creativecommons.org/licenses/by/4.0/ The Creative Commons Public Domain Dedication waiver (http://creativecommons.org/publicdomain/zero/1.0/) applies to the data made available in this article, unless otherwise stated in a credit line to the data. 


\section{Background}

Immune checkpoint inhibitors (ICI), including antibodies against cytotoxic T-lymphocyte associated antigen-4 (CTLA-4), programmed cell death-1 (PD-1), and programmed-death-ligand-1 (PD-L1), function to help the body overcome potential barriers to the recognition and elimination of cancer by the host immune system. There are numerous monotherapy and combination indications for these drugs in the management of advanced cancer. Approvals in the adjuvant setting have further expanded the population of patients with both potential benefit and toxicity from treatment $[1,2]$. Patient exposure to ICI will continue to increase, as there are several new agents in development.

Toxicities from ICI therapy, termed immune related adverse events (irAEs), can occur with any ICI agent, and can manifest any time during or after therapy. Constitutional symptoms, dermatologic, gastrointestinal, hepatic, and endocrine toxicities are the most common irAEs and management strategies are outlined in published guidelines and expert reviews [3-6]. Less common irAEs, such as cardiac and neurologic toxicities, have emerged with increasing utilization. Despite the low frequency, these complications are often serious, with a variety of clinical profiles described [6]. There are reports of fulminant fatal cardiac toxicity, electrical dysfunction, acute coronary syndrome, pericarditis, and acute systolic heart failure occurring after ICI therapy [7-13]. Defining the frequency and patterns of cardiac toxicity from ICI therapy is an area of active investigation [14]. The spectrum of neurologic toxicity can range from non-specific symptoms, such as headache and weakness, to classic findings of well-defined neurologic disorders. A 2019 pharmacovigilance study reported an increased incidence of myasthenia gravis (MG), encephalitis, peripheral neuropathy and meningitis with use of ICI therapy [15].

Despite the low frequency of these toxicities, our single academic institution managed eight patient cases since April 2016 of severe clinical illness resulting from concurrent cardiac and neurologic irAEs, all resulting in fatal outcomes.

\section{Methods}

Patients were identified through clinical care at admission to the University of Virginia (UVA) Health System. After Institutional Review Board review, we collected clinical and pathologic data related to malignancy diagnosis and treatment and past medical history. We evaluated the presentation of each subject, including clinical descriptions in progress notes, results from laboratory testing, cardiovascular analysis, and cross-sectional imaging. We outlined the immunosuppressive regimens used in each case and the recorded outcomes. Descriptive statistics were reported.

\section{Case 1}

The patient was a 70-year-old male with metastatic melanoma treated with combination ipilimumab and nivolumab. He presented on cycle 1, day 12, with palpitations, double vision, right ptosis and pre-syncope. Initial troponin was $3.65 \mathrm{ng} / \mathrm{mL}$ and creatinine kinase (CK) was 3549 U/L. Transthoracic echocardiogram (TTE) showed normal left and right ventricular (LV/RV) function and electrocardiogram (ECG) revealed sinus tachycardia, right bundle branch block, and premature atrial contractions. The patient was started on IV steroids at $1 \mathrm{mg} / \mathrm{kg}$ for presumed checkpoint inhibitor induced myocarditis. Cardiac magnetic resonance imaging (CMR) revealed evidence of myocardial edema and late gadolinium enhancement in the subepicardial mid-inferior wall consistent with acute myocarditis (Fig. 1). The patient developed progressive cardiac electrical abnormalities and the troponin continued to rise to $29.69 \mathrm{ng} / \mathrm{mL}$. Anti-thymocyte globulin (ATG) was started and the steroid dose was increased to one-gram methylprednisolone with his declining clinical status. The patient had cardiac arrest and responded to CPR. Telemetry demonstrated bradycardia with complete heart block and pacing was initiated. Patient had short periods of clinical stabilization but no sustained improvement from a cardiac or neurologic standpoint with aggressive supportive care and immunosuppression. On hospital day 5,

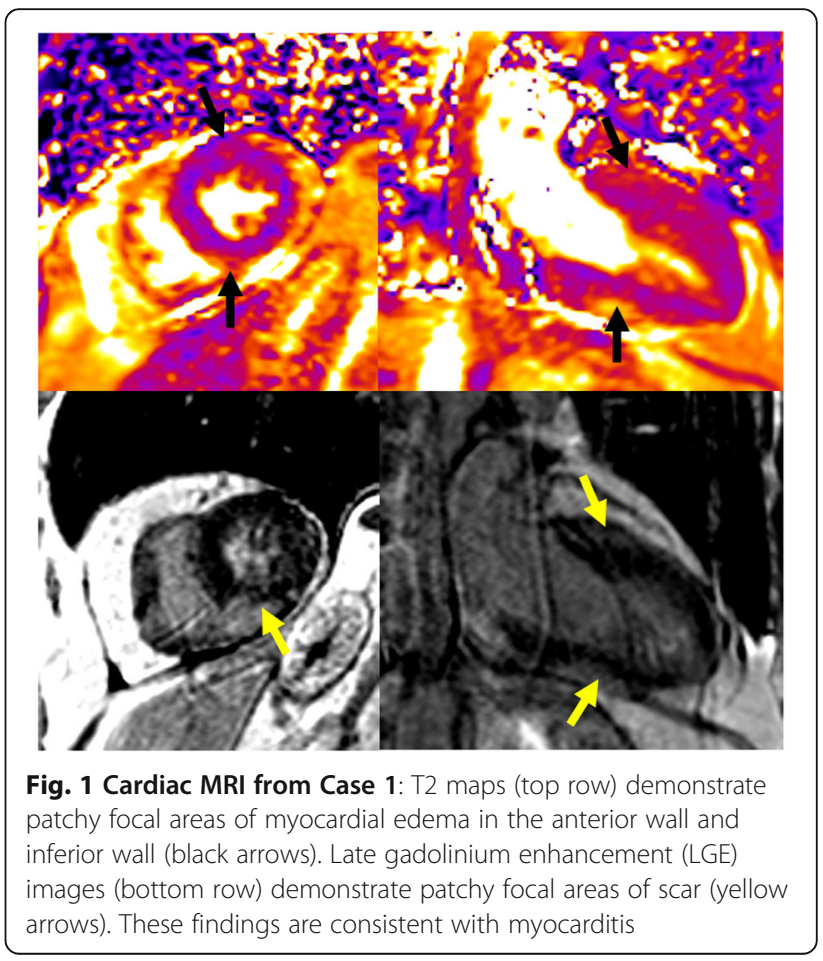


mycophenolate mofetil (MMF) and cyclophosphamide were added to the regimen but by the next day, the patient had significant global weakness with progressive bilateral ptosis and dyspnea. Plasmapheresis was started for the clinically diagnosis of Myasthenia gravis (MG) and anti-acetylcholine-receptor (AChR) antibody was positive. Repeat TTE demonstrated worsening LV and RV function with LVEF of $40-45 \%$ and troponin rose to $90.58 \mathrm{ng} / \mathrm{mL}$. He required intubation for respiratory failure, developed progressive and refractory electrical abnormalities and ultimately died after unsuccessful resuscitation efforts (Fig. 2).

\section{Case 2}

he patient was a 79-year-old male with metastatic melanoma treated with pembrolizumab. He presented with blurred vision, diplopia, fatigue, lower extremity weakness and diffuse pain. The patient was found to be in complete heart block with an initial troponin of 16.45 $\mathrm{ng} / \mathrm{mL}$ and $\mathrm{CK}$ of $11,953 \mathrm{U} / \mathrm{L}$, as well as hepatitis (ALT 395 U/L, AST 710 U/L) (Fig. 3). Bedside TTE showed a LVEF of $60-65 \%$. His exam was notable for ophthalmoplegia, bilateral fatigable ptosis, and diffuse weakness with muscle pain during strength testing. The patient was started on IV steroids at $1 \mathrm{mg} / \mathrm{kg}$ initially, but the dose was increased to $1 \mathrm{~g}$ daily on hospital day (HD) 1 along with initiation of ATG and MMF with rising biomarkers. Intravenous cyclophosphamide was started on hospital day 3. Cardiac biomarkers ultimately decreased with this therapy, to a nadir of troponin $0.34 \mathrm{ng} / \mathrm{mL}$ and CK $247 \mathrm{U} / \mathrm{L}$. He completed the planned courses of intravenous steroid and ATG and was transitioned to oral prednisone. A permanent pacemaker was placed, and he had no further cardiac events during his illness. Intravenous Immunoglobulin (IVIg) was initiated for the clinical diagnosis of MG, but there was no improvement in generalized weakness or ophthalmoplegia. His antiAChR antibody testing was negative. His course was further complicated by an upper gastrointestinal bleed due to erosive duodenopathy and a pulmonary embolism. Patient opted to transition to hospice care due to lack of significant clinical improvement.

\section{Case 3}

The patient was a 61-year-old female with metastatic breast cancer treated with combination durvalumab and tremelimumab on trial. The patient presented for dose two of therapy with several days of right ptosis and was found to have hepatitis (AST 720 U/L, ALT $327 \mathrm{U} / \mathrm{L}$ ), myositis (CK $8082 \mathrm{U} / \mathrm{L})$ and elevated troponin $(1.03 \mathrm{ng} /$ $\mathrm{mL}$ ). She was started on IV steroids at $2 \mathrm{mg} / \mathrm{kg}$ and was admitted to the hospital. TTE was performed and demonstrated LVEF of $60-65 \%$ and CMR did not show evidence of myocarditis. Urgent brain MRI was negative for brain metastases or leptomeningeal disease. For a clinical diagnosis of MG, she received pyridostigmine with symptomatic improvement. Her anti-AChR antibody testing was negative. The IV steroids induced steady improvement in transaminases, and CK. She experienced episodes of chest pain, dizziness, dyspnea, and developed premature atrial contractions and QTc prolongation on ECG (Fig. 4). Her troponin initially

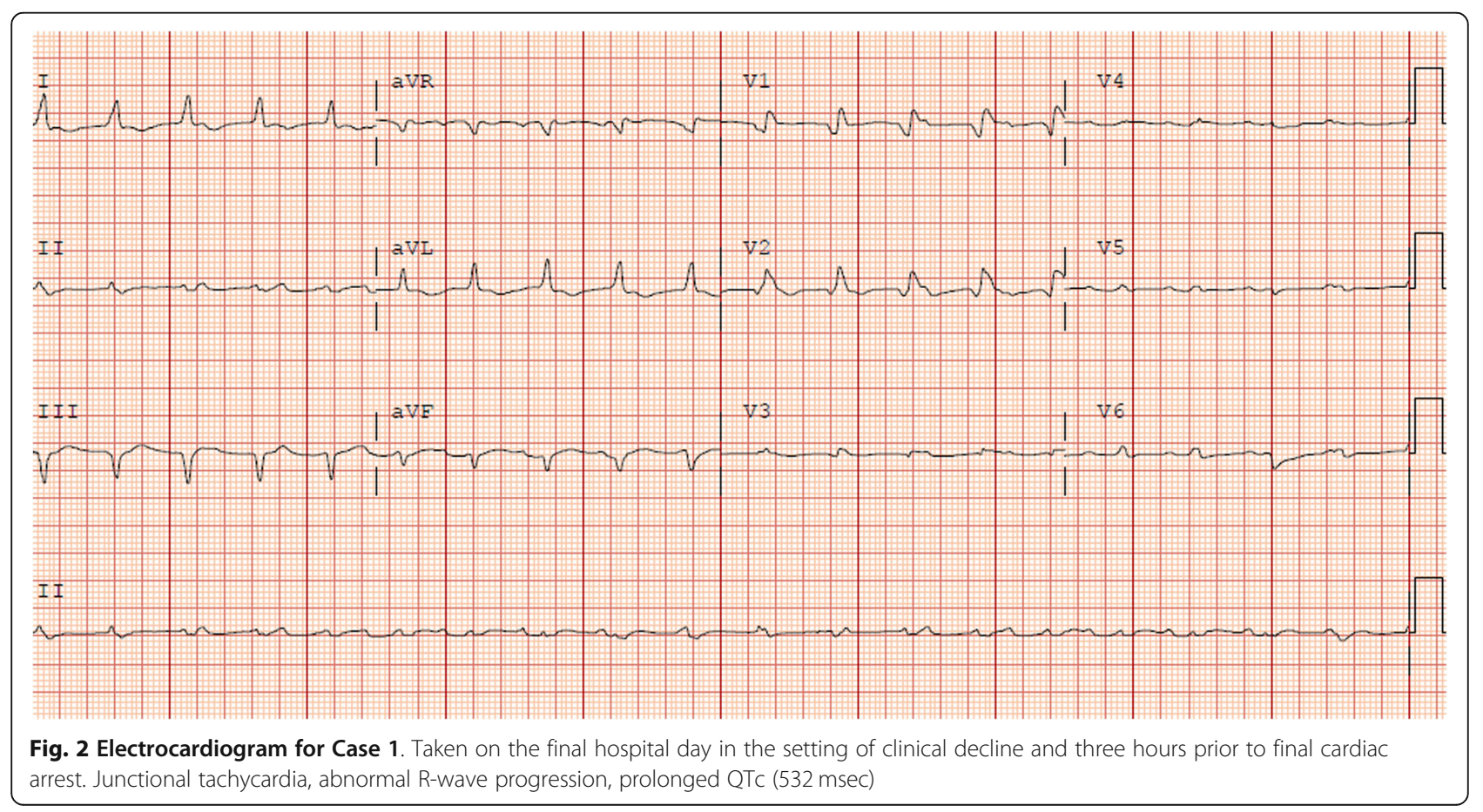




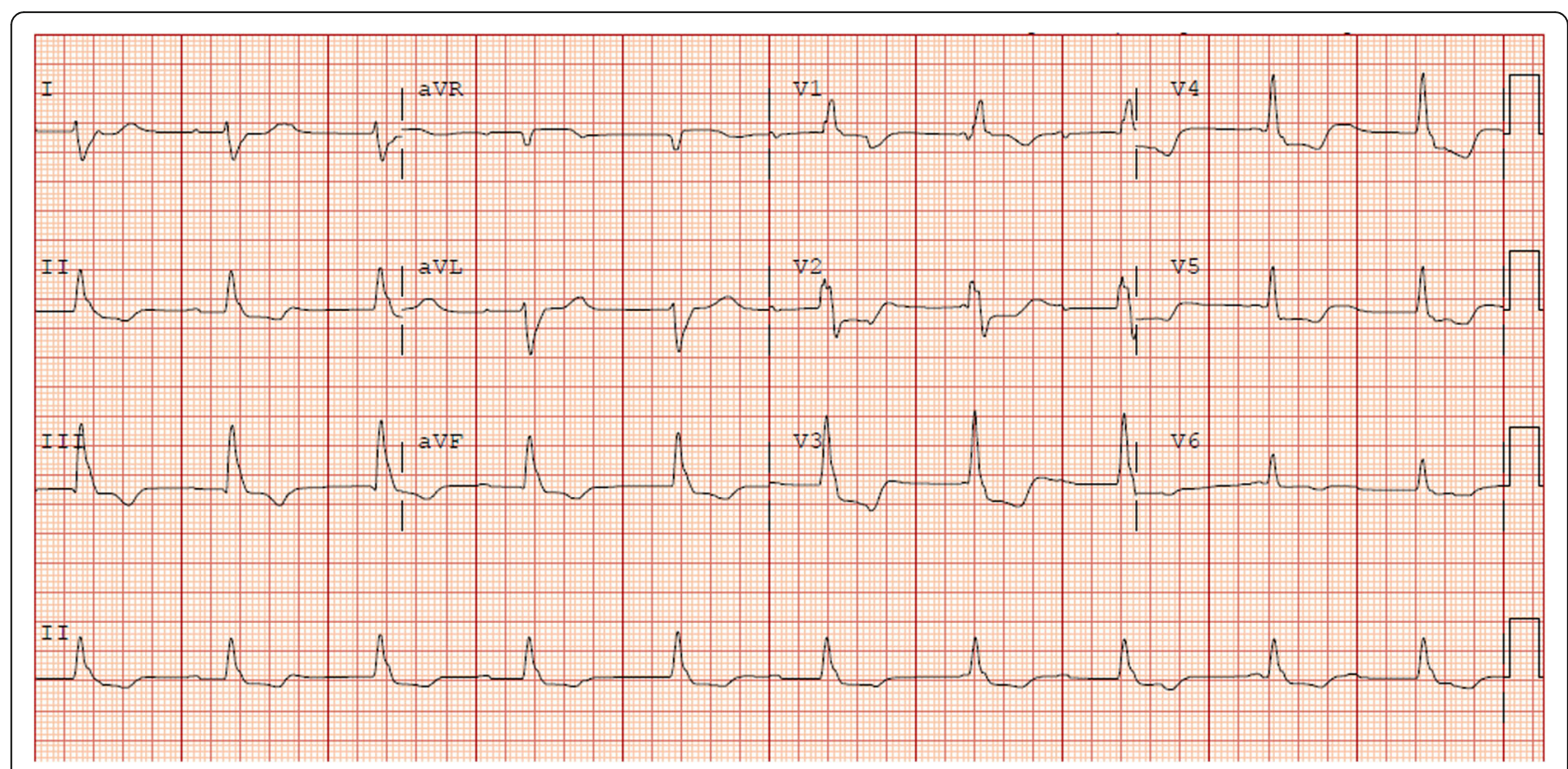

Fig. 3 Presenting Electrocardiogram for Case 2. Complete atrioventricular block with wide QRS complex

improved to $0.86 \mathrm{ng} / \mathrm{mL}$ with therapy, but on it rose again to a maximum of $1.24 \mathrm{ng} / \mathrm{mL}$. MMF was added and the troponin steadily improved to $0.65 \mathrm{ng} / \mathrm{mL}$ at discharge. She returned to the hospital within 2 days of discharge with chest pressure and dizziness. Her troponin was $0.39 \mathrm{ng} / \mathrm{dL}$ and her transaminases were also trending downward. Her sodium, normal at discharge, was 119 $\mathrm{mmol} / \mathrm{L}$ and the patient was transitioned back to IV steroids. For a diagnosis of syndrome of inappropriate antidiuretic hormone (SIADH), she required hypertonic saline. She declined quickly with the development of hypercapnic respiratory failure and was transitioned to comfort measures.

\section{Case 4}

The patient was a 69-year-old male with metastatic urothelial carcinoma treated with pembrolizumab. The patient presented with diffuse body pain and weakness

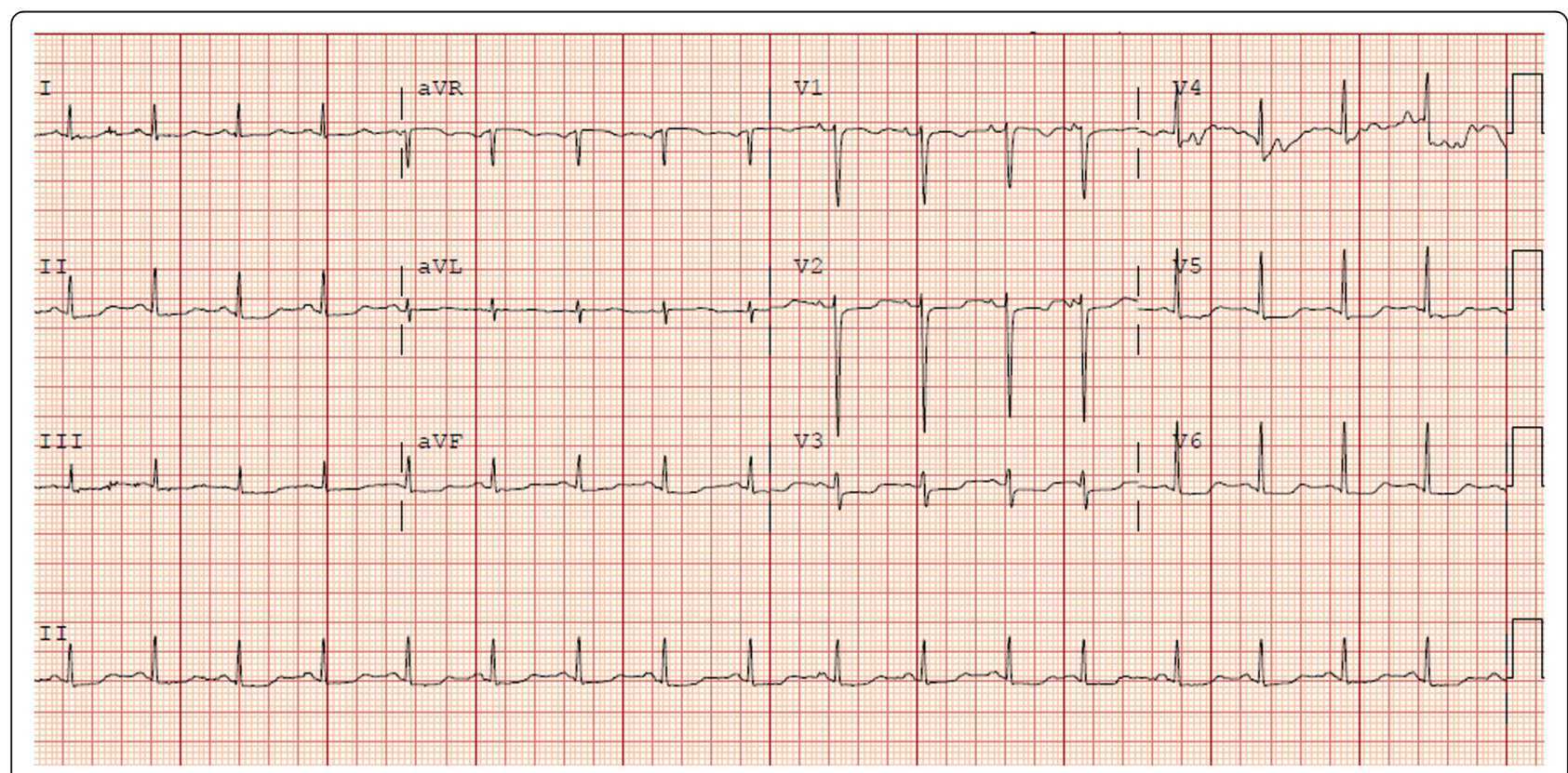

Fig. 4 Electrocardiogram from Patient 3. Taken in the setting of chest pain, dizziness and dyspnea. Prolonged QTc 519 msec (baseline $437 \mathrm{msec}$ ) 
on cycle 5 , day 2 , of pembrolizumab. His troponin was elevated at $1.42 \mathrm{ng} / \mathrm{mL}$, and he was managed for nonST-elevation myocardial infarction (NSTEMI). His troponin continued to climb to a peak of $23 \mathrm{ng} / \mathrm{mL}$ over the first $24 \mathrm{~h}$. CK peak was $372 \mathrm{U} / \mathrm{L}$ at arrival but then normalized with supportive care. TTE demonstrated mild concentric hypertrophy with EF of $40-45 \%$ and CMR was not pursued due to chronic kidney disease. IV steroids were initiated at $1 \mathrm{mg} / \mathrm{kg}$ initially along with MMF given concern for ICI-induced myocarditis. Cardiac catheterization did not show evidence of acute coronary artery obstruction. A course of ATG was initiated and the steroids were increased to one gram of methylprednisolone daily for rising cardiac biomarkers. The patient clinically improved and troponin levels peaked at $58.99 \mathrm{ng} / \mathrm{mL}$ on HD 6 and then decreased to $20.21 \mathrm{ng} / \mathrm{mL}$ by the end of the clinical course. CK remained low and no clinically significant cardiac electrical abnormalities were identified. The presenting global weakness, disconjugate gaze and diffuse body pain did not improve. On HD 4, the patient developed altered mental status due to multiple cerebrovascular accidents resulting in left hemiparesis. Further workup for the etiology of the strokes was unrevealing, with vasculitis or cholesterol-emboli from the catheterization as the leading considerations. The patient opted to transition to comfort measures.

\section{Case 5}

The patient was a 67-year-old female with metastatic melanoma treated with combination ipilimumab and nivolumab. She presented on cycle 1 day 5 with diffuse body weakness, dyspnea, and dysphagia and was found to have hepatitis (ALT $563 \mathrm{U} / \mathrm{L}$, AST $353 / \mathrm{L}$ ) and a troponin of $1.8 \mathrm{ng} / \mathrm{mL}$. Once hospitalized, she soon developed hypercapnic respiratory failure and was intubated. TTE demonstrated preserved EF, pro-B-type NP was $1370 \mathrm{pg} / \mathrm{mL}$, and CK was $7244 \mathrm{IU} / \mathrm{L}$. She was considered unstable for cardiac catheterization. Patient was started on IV steroids at $2 \mathrm{mg} / \mathrm{kg}$ and MMF. The troponin rose to $12.02 \mathrm{ng} / \mathrm{mL}$, while CK and transaminases trended down. With failure to clinically improve, she was transferred to our institution and the steroids were increased to methylprednisolone $1 \mathrm{~g}$ per day and ATG was added. Repeat TTE demonstrated an EF of 60-65\%. Her troponin peaked at $18.42 \mathrm{ng} / \mathrm{dL}$ and then declined. CMR was performed 8 days after starting immunosuppression with improving cardiac biomarkers (CK 231, Troponin 1.86) and did not demonstrate imaging evidence of myocarditis. Immunosuppression was tapered and cardiac and hepatic biomarkers showed steady improvement. The patient remained ventilatordependent due to respiratory muscle weakness from a clinical diagnosis of MG. Her anti-AChR antibody testing was positive. Plasmapheresis was initiated but failed to impact her clinical status and she was transitioned to comfort measures.

\section{Case 6}

The patient was an 83-year-old male with melanoma treated with nivolumab in the adjuvant setting. One month after his first dose, he developed marked fatigue, weakness, chest pain and orthopnea. His troponin was $0.78 \mathrm{ng} / \mathrm{mL}$ and he was diagnosed with pericarditis and medically managed with colchicine and naproxen. The next day, he presented again with chest tightness, dysphagia, and progressive left eye ptosis. TTE showed LVEF of $55 \%$ and treatment for pericarditis was continued. On examination, he had proximal muscle weakness, areflexia and ocular muscle abnormalities. He had both hepatitis (ALT $166 \mathrm{U} / \mathrm{L}$, AST $510 \mathrm{U} / \mathrm{L}$ ) and an elevated CK (2886 U/L). MRI of the brain was unremarkable. The patient was started on IV methylprednisolone at $1 \mathrm{mg} / \mathrm{kg}$ and plasmapheresis was started for a clinical diagnosis of MG. His anti-AChR antibody testing was negative. He required intubation for hypercapnic respiratory failure. Over the course of the next several days his troponin, $\mathrm{CK}$ and liver function tests all improved, but he had persistent respiratory compromise with inability to reduce ventilatory support. The patient was transitioned to comfort measures.

\section{Case 7}

The patient was a 70-year-old male with metastatic kidney cancer treated with ipilimumab and nivolumab in combination. He presented on cycle 1 day 21 with generalized weakness and fatigue. He was identified to have a $\mathrm{CK}$ of $11,000 \mathrm{U} / \mathrm{L}$ and troponin of $36 \mathrm{ng} / \mathrm{mL}$. The patient was treated with IV steroids and supportive care with stabilization of clinical status and biochemical improvement. He was discharged to a rehabilitation facility and transitioned to oral prednisone for a taper. The patient clinically deteriorated with progressive dysphagia, globus sensation, dyspnea and weakness on prednisone at 60 $\mathrm{mg}$ (approximately $0.5 \mathrm{mg} / \mathrm{kg}$ ). He was admitted with a clinical diagnosis of ICI-induced MG and plasmapheresis was started. His anti-AChR antibody testing was negative. The patient required intubation for respiratory failure and then the steroids were increased to methylprednisolone $1 \mathrm{~g}$ per day. His troponin level peak value was $0.28 \mathrm{ng} / \mathrm{mL}$ on this hospitalization. His echocardiogram demonstrated a preserved LVEF of $60-65 \%$ and no major rhythm abnormalities were identified. He developed upper gastrointestinal bleeding from immunerelated gastritis and Infliximab was given. The patient had persistent respiratory failure and was transitioned to comfort measures. 


\section{Case 8}

The patient is an 89-year-old male with non-small cell lung cancer treated with pembrolizumab. The patient presented 10 days after dose 2 with disconjugate gaze, dysphagia, blurred vision and imbalance and was found to have hepatitis (ALT $243 \mathrm{U} / \mathrm{L}, \mathrm{AST} 416 \mathrm{U} / \mathrm{L}$ ). For a clinical diagnosis of MG, he was started on IV steroids at $1 \mathrm{mg} / \mathrm{kg}$. The anti-AChR testing was negative. He had an elevated troponin to $1.66 \mathrm{ng} / \mathrm{mL}$ at presentation that peaked at $2.34 \mathrm{ng} / \mathrm{mL}$, favored clinically to be checkpoint-inhibitorinduced myocarditis. TTE was technically limited and cardiac MRI had evidence of a prior infarct with no clear evidence of myocarditis and an ejection fraction of $47 \%$. He showed multiple episodes of non-sustained ventricular tachycardia and developed high-degree atrioventricular block. For elevated CK to 3843 U/L, he underwent EMG showing myopathic changes expected with myositis. Liver function tests and CK improved with steroids but patient had persistent weakness, dysphagia and blurred vision. The patient and family opted to pursue comfort measures.

\section{Results}

\section{Clinical and oncologic data}

Eight successive cases of combined neurologic and cardiac toxicities presented to the UVA Health System, including four patients who received oncologic care outside of our institution and were transferred for toxicity management (Table 1). This group included six males and two females, all Caucasian, with an average age of 73.5 years (range, 61-89 years). There were five diseases represented, including four patients with melanoma, and one patient each with urothelial carcinoma, breast carcinoma, renal cell carcinoma, and non-small cell lung cancer.

Four patients received combination anti-CTLA4 and anti-PD1, including two patients with melanoma, one with breast cancer and one patient with renal cell carcinoma (Table 1). Four patients received anti-PD-1 monotherapy, including one patient being treated in the adjuvant setting for melanoma. Five patients had baseline cardiovascular comorbidities, including coronary artery disease, hypertension, type 2 diabetes mellitus, and atrial fibrillation (Table 1). One patient had a concurrent diagnosis of chronic lymphocytic leukemia requiring chemotherapy and one patient had a remote history of resected colon cancer. None had prior autoimmune disease.

\section{Toxicity presentation}

The patients presented at a median of 27 days (range, 11-132 days) from the initiation of ICI therapy. All cases had a cardiovascular toxicity recognized early in the acute presentation (Table 2). Seven cases had a clinical syndrome consistent with myocarditis, including three with high-degree atrioventricular conduction block. The eighth patient was diagnosed with pericarditis. All patients were diagnosed with presumed checkpointinhibitor myocarditis based on clinical features (history, examination, biomarkers, electrocardiogram and cardiac imaging) and each patient was assessed by a Cardiology specialist. There were no cardiac biopsies or autopsies performed for histologic assessment.

All cases had a neurologic toxicity, primarily MG (Table 2). The eighth patient had multiple strokes. Of the cases of MG, five had ophthalmoplegia and four developed respiratory failure requiring intubation. Most patients had concurrent myositis, diagnosed by elevated creatine kinase $(\mathrm{CK})$ and clinical symptoms. There were no muscle biopsies performed but one patient had characteristic myositis findings on EMG. All patients were evaluated by Neurology specialists.

Two patients developed severe gastritis/duodenitis with upper gastrointestinal bleeding, favored immune in origin. Gastric biopsy from case seven showed findings consistent with checkpoint inhibitor gastritis. One patient ultimately died of hypercapnic respiratory failure in the setting of complications from the syndrome of inappropriate anti-diuretic hormone (SIADH) and the relationship with the checkpoint inhibitor therapy is not known.

\section{Toxicity treatment}

Multiple immunosuppressive agents were used in each case. All patients were treated with steroids with starting doses between 1 and $2 \mathrm{mg} / \mathrm{kg}$ and additional agents were added in a stepwise approach determined by the patient's clinical status and response. Steroids were continued for the duration of the clinical course. Guidelines from the American Society of Clinical Oncology (ASCO) and the National Comprehensive Cancer Network $\left(\mathrm{NCCN}^{\circ}\right)$ were followed and expert opinion was sought within and outside of our academic medical center. Four patients ultimately received five-day courses of one-gram intravenous methylprednisolone. Several of these patients presented within months of each other, which impacted the immunosuppression dosing and agent timing and selection. Four patients (50\%) received antithymocyte globulin, four $(50 \%)$ received mycophenolate mofetil, and two patients (25\%) had cyclophosphamide added to the regimen for lymphodepletion in the setting of persistent clinical illness. For the MG, all patients were treated symptomatically with pyridostigmine. Four patients (50\%) underwent plasmapheresis and one received intravenous immunoglobulin. One patient received infliximab for irAE management. The early immunosuppressant choices were targeted at the cardiac abnormalities and the antibody depleting therapies for MG tended to start in the first several days of admission. 
Table 1 Demographics and Patient Information

\begin{tabular}{|c|c|c|c|c|c|c|}
\hline Case & Age & Sex & Disease & ICI Therapy & $\begin{array}{l}\text { Time to Presentation from ICI } \\
\text { Initiation }\end{array}$ & Baseline Medical History \\
\hline 1 & 70 & Male & Melanoma & $\begin{array}{l}\text { Ipilimumab/ } \\
\text { Nivolumab }\end{array}$ & 11 Days & Hypertension Colon Cancer \\
\hline 2 & 79 & Male & Melanoma & Pembrolizumab & 26 Days & $C L L$ \\
\hline 3 & 61 & Female & Breast Cancer & $\begin{array}{l}\text { Durvalumab/ } \\
\text { Tremelimumab }\end{array}$ & 28 Days & None \\
\hline \multirow[t]{3}{*}{4} & 69 & Male & Urothelial Carcinoma & Pembrolizumab & 132 Days & CKD, Hypertension, Hyperlipidemia \\
\hline & & & & & & Type 2 DM \\
\hline & & & & & & $C A D$ \\
\hline 5 & 67 & Female & Melanoma & $\begin{array}{l}\text { Ipilimumab/ } \\
\text { Nivolumab }\end{array}$ & 14 Days & None \\
\hline \multirow[t]{3}{*}{6} & 83 & Male & Melanoma & Nivolumab, Adjuvant & 31 Days & Hypertension, \\
\hline & & & & & & Hyperlipidemia \\
\hline & & & & & & Atrial fibrillation \\
\hline 7 & 70 & Male & Renal Cell Carcinoma & $\begin{array}{l}\text { Ipilimumab/ } \\
\text { Nivolumab }\end{array}$ & 21 Days & Hypertension, CKD, Atrial Fibrillation \\
\hline 8 & 89 & Male & $\begin{array}{l}\text { Non-Small Cell Lung } \\
\text { Carcinoma }\end{array}$ & Pembrolizumab & 32 Days & $\begin{array}{l}\text { Hypertension, Hyperlipidemia, CAD, CKD, } \\
\text { Type } 2 \text { DM }\end{array}$ \\
\hline
\end{tabular}

Baseline data, disease and treatment information for each patient. CLL chronic lymphocytic leukemia, CAD coronary artery disease, Type 2 DM type 2 diabetes mellitus, CKD chronic kidney disease

\section{Outcomes}

All patients died as a result of the immunotherapy toxicity (Table 3 ). The average time between the last treatment and death was 32.5 days (range, 17-67 days). One patient died rapidly in the hospital despite maximal interventions. The other seven opted for withdrawal of aggressive care with transition to comfort measures. In six cases $(75 \%)$, the cardiac components improved with down-trending biomarkers, maintenance of stable ejection fraction, and lack of significant electrical instability apart from the pacemaker required for cases with complete heart block. One patient died of progressive cardiac failure on a fulminant course. One patient was showing developing cardiac electrical changes including high-degree atrioventricular block at the time that care was transitioned to comfort measures.
Only one case had notable improvement from the neurologic toxicity and the generalized weakness was a prominent aspect of the toxicity course for each patient. None of the patients with respiratory failure requiring mechanical ventilation recovered sufficiently to be removed from the ventilator. As each of these patients and/or families made the decision to withdraw care, the trajectory and potential neurologic and respiratory recovery with prolonged support is not known.

Six of the seven (86\%) cases with myositis showed significant improvement in CK levels with immunosuppression. Six of the seven (86\%) of the cases with hepatitis showed significant improvement in transaminase levels with immunosuppression. The seventh patient in both of these groups discontinued interventions prior to evidence of improvement.

Table 2 Range of toxicities for each case

\begin{tabular}{|c|c|c|c|c|c|c|}
\hline Case & Cardiovascular Toxicity & Neurologic/Ocular Toxicity & Myositis & Hepatitis & Respiratory Failure & Other \\
\hline 1 & Myocarditis Complete Heart Block & Myasthenia Gravis & + & + & + & - \\
\hline 2 & Myocarditis, Complete Heart Block, Pulmonary Embolism & Myasthenia Gravis & + & + & - & Gastritis \\
\hline 3 & Myocarditis & Myasthenia Gravis & + & + & - & SIADH \\
\hline 4 & Myocarditis & Stroke & - & - & - & - \\
\hline 5 & Myocarditis & Myasthenia Gravis & + & + & + & - \\
\hline 6 & Pericarditis & Myasthenia Gravis & + & + & + & - \\
\hline 7 & Myocarditis & Myasthenia Gravis & + & + & + & Gastritis \\
\hline 8 & Myocarditis, Complete Heart Block & Myasthenia Gravis & + & + & - & - \\
\hline
\end{tabular}

Each case had multiple overlapping toxicities after presenting with primarily a cardiac symptom. SIADH syndrome of inappropriate anti-diuretic hormone 
Table 3 Patient Outcome

\begin{tabular}{|c|c|c|c|c|c|c|c|c|}
\hline Case & $\begin{array}{l}\text { Cardiac } \\
\text { Improvement }\end{array}$ & $\begin{array}{l}\text { Neurologic } \\
\text { Improvement }\end{array}$ & $\begin{array}{l}\text { Myositis } \\
\text { Improvement }\end{array}$ & $\begin{array}{l}\text { Hepatitis } \\
\text { Improvement }\end{array}$ & $\begin{array}{l}\text { Respiratory } \\
\text { Improvement }\end{array}$ & $\begin{array}{l}\text { Cancer } \\
\text { Response }\end{array}$ & $\begin{array}{l}\text { Withdrawal of Care/ } \\
\text { Hospice Decision }\end{array}$ & $\begin{array}{l}\text { Time from last } \\
\text { treatment to Death }\end{array}$ \\
\hline 1 & - & - & + & + & - & SD & - & 17 Days \\
\hline 2 & + & - & + & + & NA & $P R$ & + & 21 Days \\
\hline 3 & + & + & + & + & NA & $N R$ & + & 41 Days \\
\hline 4 & + & - & NA & NA & NA & SD & + & 17 Days \\
\hline 5 & + & - & + & + & - & SD & + & 34 Days \\
\hline 6 & + & - & + & + & - & NA & + & 42 Days \\
\hline 7 & + & - & + & + & - & $N R$ & + & 67 Days \\
\hline 8 & - & - & - & - & NA & $N R$ & + & 21 Days \\
\hline
\end{tabular}

Outcome of immunosuppression on toxicity course by organ system and overall course. For organ toxicities " + " = improved, "- "= did not improve. NA Not applicable, SD stable disease, $P R$ Partial response, $N R$ Not reported

Four of the eight (50\%) cases had cross-sectional imaging done during the disease course that allowed assessment of cancer response to therapy. Of these four, one patient showed a partial response to therapy and three had stable disease.

\section{Discussion}

Toxicities from ICI are variable in onset, presentation, and severity. In current experience, there are no patient or tumor characteristics that reliably predict irAEs. Our cases included men and women, ages from 61 to 83 years, with varied cancers and ICI-treatments represented (Table 1). All patients had metastatic disease, including one patient that had undergone melanoma resection to no evidence of disease and was receiving therapy in the adjuvant setting. Three patients had minimal comorbid conditions. Each patient had evidence of a cardiovascular insult and a neurologic insult, and most had concurrent hepatitis and myositis. Toxicities tended to onset early following initiation of ICI therapy, often after the first dose. In this cohort, the cardiovascular signs and symptoms were visible early in the presentation and were the focus of initial diagnostics and immunosuppressive interventions. The neurologic insults, however, proved to be the most symptomatic and the primary determinants of the clinical course.

Cardiac toxicity from ICI therapy was a rare immunerelated adverse event in the early ICI trials, but this complication is becoming increasingly recognized and reported [16, 17]. In one series of over 20,000 patients treated with nivolumab, ipilimumab or combined ipilimumab and nivolumab, cardiovascular irAEs were rare (0.09\%) [7]. In addition, Mahmood identified an overall incidence of myocarditis of $1.14 \%$ from a multicenter registry [18]. With increasing use of ICI agents, the spectrum of associated cardiovascular toxicity is expanding. In this cohort, clinical profiles included fulminant myocarditis, complete heart block, QTc prolongation, pulmonary embolism, and pericarditis. Each patient also had several concurrent irAEs, many with overlapping myocarditis, myositis, and Myasthenia gravis. In 2018, Moslehi et al. reported on 101 cases of severe myocarditis from ICI therapy and noted that in $42 \%$ of cases, there was a concurrent severe irAE, most commonly myositis and Myasthenia [19]. Mortality reported from these cases of myocarditis ranged from 36\% for patients treated with anti-PD-1 or anti-PD-L1 antibodies to $67 \%$ for patients treated with combination anti-CTLA-4 and anti-PD1/PD-L1 therapy.

In 2016, Johnson reported two cases of fulminant myocarditis in patients receiving combination ipilimumab and nivolumab for advanced melanoma [8]. Both patients received aggressive immunosuppression and supportive care but quickly died from the irAE. The clinical course for two of our cases followed a similar fulminant pattern with early onset symptoms after ICI initiation, electrical instability, and rapid clinical deterioration. One patient died and one patient survived the initial cardiac instability. For most of our patients, the cardiac insults proved manageable in the short term with aggressive supportive care, including device placement and immunosuppression, evidenced by preserved ejection fraction, lack of major electrical dysfunction, and improving cardiac biomarkers. As each patient died, we can make no comments regarding the long-term cardiac outcomes.

Seven of our cases had a clinical syndrome consistent with Myasthenia gravis. MG occurs in approximately $0.15 \%$ of patients treated with anti-PD1 therapy [20]. This is an antibody-mediated disorder of the postsynaptic membrane at the neuromuscular junction, and, in its severe form, can impact respiratory muscle function $[21,22]$. The diagnosis of MG is usually clinical but can be supported by the presence of autoantibodies, typically against the acetylcholine receptor [21]. In each of our cases, the MG diagnosis was made on clinical 
grounds by a Neurologist. Antibody testing was done on each patient, but results took several days to return, and treatment decisions were required without the results. There are several other autoantibodies less commonly implicated in the development of MG, including antibodies against the voltage-gated potassium channel Kv1.4, which are associated with cardiac involvement of the Myasthenia [23, 24]. Treatment for MG often includes immunosuppression and antibody-depleting therapy, such as plasmapheresis and/or intravenous immunoglobulin. While corticosteroids are the mainstay of management for irAEs, there is a concern about worsening of weakness early in the course of MG with initiation of steroids. Early multidisciplinary input is invaluable to management of these complex toxicities.

As with all irAEs, ICI-induced MG presents with a spectrum of severity with some patients only developing limited symptoms that respond to immunosuppression and pyridostigmine [25, 26]. Overall, ICI-induced MG tends to have a more aggressive clinical course than non-ICI-related disease and patients often show signs of myositis and myocarditis [20,27]. The triad of MG, myositis and myocarditis has been reported in case reports of ICI-treated patients with a variety of cancers [20, 28-34]. Suzuki et al. reported the results of a safety database in Japan including outcomes of 10,277 patients treated with either single-agent nivolumab or ipilimumab [27]. Twelve patients developed MG, with early onset of symptoms with rapid clinical deterioration. Ten of these 12 patients had elevated CK levels, four with confirmed concurrent myositis, and three with concurrent myocarditis. Six of these patients developed a myasthenic crisis including five patients that required respiratory support for a median duration of 54 days (range 10-128 days). The authors report that the patients with severe myasthenia had a slow recovery with improvement in muscle strength occurring over 4-8 weeks. In a review by Kao et al., the rates of respiratory failure with ICI-induced MG were as high as $50 \%$ of reported cases, and most patients presented with elevated levels of CK [20]. In our cohort, four patients out of seven with a clinical syndrome of MG required intubation for respiratory failure and each had an elevated CK.

Clinically significant objective and subjective weakness was a prominent issue throughout the clinical course for most of our cases. In the setting of advanced cancer, the marked clinical deterioration and prolonged duration of symptoms were central components of the care decisions. Seven of the patients opted to transition to best supportive care due to ongoing setbacks and/or severe weakness after 2-4weeks of aggressive care. Despite objective improvements in measurable laboratory and clinical parameters, and supportive interventions for mobility and strength, the patient-reported weakness failed to meaningfully improve. In contrast to the expected rapid improvement with immunosuppression often seen in management of most irAEs, the clinical course for our cases was strikingly different with improvement in objective measures, but minimal overall clinical change for these patients. Providers should be aware of the potential long duration of illness and debility from some severe irAEs in order to counsel patients and family members, as these expectations will likely factor into care decisions.

We remain without clinical, pathologic, or pharmacologic predictive features for the development of the combination of cardiac and neurologic irAEs and therefore, oncologists and patients balance the risk of rare serious toxicity with the substantial potential benefit of the treatments. The heterogeneity of our cases reflects the general experience that these toxicities can impact any patient on any checkpoint inhibitor and providers need to be aware of the potential for rapid onset of toxicity and clinical deterioration. The potential for long and slow recovery is an important expectation to set with patients experiencing certain combined irAEs. Providers are encouraged to evaluate for overlapping irAEs particularly in the setting of severe presentations and a multidisciplinary management approach should be strongly considered. The morbidity and mortality from these rare irAEs will take on additional significance as the ICI agents move further into the adjuvant setting.

\section{Conclusions}

In the evaluation of patients with cardiac adverse events from immunotherapy, providers should evaluate for overlapping toxicities such as myasthenia gravis and myositis. Providers should be aware of the potential for an extended duration of disability and slow improvement for certain toxicities as these expectations may factor prominently in goals of care decisions.

\section{Abbreviations \\ ICl: Immune checkpoint inhibition; CTLA-4: Cytotoxic T-lymphocyte associ- ated protein-4; PD-1: Programmed cell death protein 1; PD-L1: Programmed death-ligand 1; irAEs: Immune-related adverse events; MG: Myasthenia gravis; UVA: University of Virginia; CK: Creatine Kinase; SIADH: Syndrome of inappropriate anti-diuretic hormone; CLL: Chronic lymphocytic leukemia; CAD: Coronary artery disease; CKD: Chronic kidney disease; Type 2 DM: Type 2 diabetes mellitus; ATG: Anti-thymocyte globulin; MMF: Mycophenolate mofetil; Cyclophos: Cyclophosphamide; IVlg: Intravenous immunoglobulin}

\section{Acknowledgements}

Not applicable.

\section{Authors' contributions}

PA contributed to the design of the study, obtained patient data and wrote and edited the manuscript. LT contributed to the design of the study, obtained patient data and wrote and edited the manuscript. PD provided patient care to one of the cases, contributed to the concept and design of the study and edited the manuscript. RG provided patient care to two of the cases, contributed to the concept and design of the study and edited the 
manuscript. TM provided patient care to one of the cases and edited the manuscript. MS provided cardiology imaging and patient care to several of the cases and edited the manuscript. CLS contributed to the design of the study and edited the manuscript. EG contributed to the design of the study, obtained patient data, edited the manuscript and submitted for publication. All authors read and approved the final manuscript.

\section{Funding}

There was no funding source for this manuscript.

Sources of support that require acknowledgement: This work was supported by the UVA Cancer Center Support Grant P30CA044579.

\section{Availability of data and materials}

Data sharing is not applicable to this article as no datasets were generated or analyzed during the current study.

\section{Ethics approval and consent to participate}

Request to review and report on deceased patient records was reviewed by the University of Virginia Institutional Review Board and did not require approval.

\section{Consent for publication}

Not applicable.

\section{Competing interests}

The authors declare that they have no competing interests.

\section{Author details}

${ }^{1}$ University Hospitals Siedman Cancer Center, Westlake, OH, USA. ${ }^{2}$ Department of Medicine, Division of Hematology, Duke University, Durham, NC, USA. ${ }^{3}$ Department of Medicine, Division of Hematology and Medical Oncology, University of Virginia, PO Box 800716, Charlottesville, VA 22908, USA. ${ }^{4}$ Department of Medicine, Division of Cardiovascular Medicine, Noninvasive Cardiovascular Imaging, Nuclear Medicine, University of Virginia, Charlottesville, VA, USA. ${ }^{5}$ Department of Surgery, Division of Surgical Oncology, University of Virginia, Charlottesville, VA, USA.

Received: 1 July 2020 Accepted: 11 September 2020 Published online: 23 September 2020

\section{References}

1. Weber J, Mandala M, Del Vecchio M, Gogas HJ, Arance AM, Cowey CL, et al. Adjuvant nivolumab versus ipilimumab in resected stage III or IV melanoma. N Engl J Med. 2017 Nov 09;377(19):1824-35. https://doi.org/10.1056/ NEJMoa1709030.

2. Antonia SJ, Villegas A, Daniel D, Vicente D, Murakami S, Hui R, et al. Durvalumab after chemoradiotherapy in stage III non-small cell lung cancer. N Engl J Med. 2017:377(20):1919-29. https://doi.org/10.1056/ NEJMoa1709937.

3. Puzanov I, Diab A, Abdallah K, Bingham CO 3rd, Brogdon C, Dadu R, et al. Managing toxicities associated with immune checkpoint inhibitors: consensus recommendations from the Society for Immunotherapy of Cancer (SITC) toxicity management working group. J Immunother Cancer. 2017;5(1):95. https://doi.org/10.1186/s40425-017-0300-z.

4. Weber JS, Yang JC, Atkins MB, Disis ML. Toxicities of immunotherapy for the practitioner. J Clin Oncol. 2015;33(18):2092-9. https://doi.org/10.1200/JCO. 2014.60.0379.

5. Postow MA, Sidlow R, Hellmann MD. Immune-related adverse events associated with immune checkpoint blockade. N Engl J Med. 2018;378(2): 158-68. https://doi.org/10.1056/NEJMra1703481.

6. Brahmer JR, Lacchetti C, Schneider BJ, Atkins MB, Brassil KJ, Caterino JM, et al. Management of immune-related adverse events in patients treated with immune checkpoint inhibitor therapy: American Society of Clinical Oncology clinical practice guideline. J Clin Oncol. 2018;36(17):1714-68. https://doi.org/10.1200/JCO.2017.77.6385.

7. Johnson DB, Balko JM, Compton ML, Chalkias S, Gorham J, Xu Y, et al. Fulminant myocarditis with combination immune checkpoint blockade. N Engl J Med. 2016;375(18):1749-55. https://doi.org/10.1056/NEJMoa1609214.

8. Behling J, Kaes J, Munzel T, Grabbe S, Loquai C. New-onset third-degree atrioventricular block because of autoimmune-induced myositis under treatment with anti-programmed cell death-1 (nivolumab) for metastatic melanoma. Melanoma Res. 2017;27(2):155-8. https://doi.org/10.1097/CMR. 0000000000000314

9. Heinzerling L, Ott PA, Hodi FS, Husain AN, Tajmir-Riahi A, Tawbi H, et al. Cardiotoxicity associated with CTLA4 and PD1 blocking immunotherapy. J Immunother Cancer. 2016;4(1):50. https://doi.org/10.1186/s40425-016-0152-y.

10. Läubli H, Balmelli C, Bossard M, Pfister O, Glatz K, Zippelius A. Acute heart failure due to autoimmune myocarditis under pembrolizumab treatment for metastatic melanoma. J Immunother Cancer. 2015;3(1):11. https://doi.org/10. 1186/s40425-015-0057-1.

11. Mehta A, Gupta A, Hannallah F, Koshy T, Reimold S. Myocarditis as an immune-related adverse event with ipilimumab/nivolumab combination therapy for metastatic melanoma. Melanoma Res. 2016;26(3):319-20. https:// doi.org/10.1097/CMR.0000000000000251.

12. Tomita Y, Sueta D, Kakiuchi Y, Saeki S, Saruwatari K, Sakata S, et al. Acute coronary syndrome as a possible immune-related adverse event in a lung cancer patient achieving a complete response to anti-PD-1 immune checkpoint antibody. Ann Oncol. 2017;28(11):2893-5. https://doi.org/10. 1093/annonc/mdx326.

13. de Almeida DV, Gomes JR, Haddad FJ, Buzaid AC. Immune-mediated pericarditis with pericardial tamponade during nivolumab therapy. J Immunother. 2018:41(7):329-31. https://doi.org/10.1097/CJI. 0000000000000217

14. Bonaca MP, Olenchock BA, Salem J, Wiviott SD, Ederhy S, Cohen A, et al. Myocarditis in the setting of cancer therapeutics. Proposed case definitions for emerging clinical syndromes in cardio-oncology. Circulation. 2019;140(2): 80-91. https://doi.org/10.1161/CIRCULATIONAHA.118.034497.

15. Johnson DB, Manouchehri A, Haugh AM, Quach HT, Balko JM, LebrunVignes $B$, et al. Neurologic toxicity associated with immune checkpoint inhibitors: a pharmacovigilance study. J Immunother Cancer. 2019;7(1):134. https://doi.org/10.1186/s40425-019-0617-x.

16. Postow MA, Chesney J, Pavlick AC, Robert C, Grossmann K, McDermott D, et al. Nivolumab and ipilimumab versus ipilimumab in untreated melanoma. N Engl J Med. 2015;372(21):2006-17. https://doi.org/10.1056/ NEJMoa1414428.

17. Voskens CJ, Goldinger SM, Loquai C, Robert C, Kaehler KC, Berking C, et al. The price of tumor control: an analysis of rare side effects of anti-CTLA-4 therapy in metastatic melanoma from the ipilimumab network. PLoS One. 2013;8(1):e53745. https://doi.org/10.1371/journal.pone.0053745.

18. Mahmood SS, Fradley MG, Cohen JV, Nohria A, Reynolds KL, Heinzerling LM, et al. Myocarditis in patients treated with immune checkpoint inhibitors. J Am Coll Cardiol. 2018;71(16):1755-64. https://doi.org/10.1016/j.jacc.2018.02. 037.

19. Moslehi JJ, Salem JE, Sosman JA, Lebrun-Vignes B, Johnson DB. Increased reporting of fatal immune checkpoint inhibitor-associated myocarditis. Lancet. 2018;391(10124):933. https://doi.org/10.1016/S0140-6736(18)30533-6.

20. Kao JC, Brickshawana A, Liewluck T. Neuromuscular complications of programmed cell death-1 (PD-1) inhibitors. Curr Neurol Neurosci Rep. 2018; 18(10):63. https://doi.org/10.1007/s11910-018-0878-7.

21. Gilhus NE, Skeie GO, Romi F, Lazaridis K, Zisimopoulou P, Tzartos S. Myasthenia gravis - autoantibody characteristics and their implications for therapy. Nat Rev Neurol. 2016;12(5):259-68. https://doi.org/10.1038/nrneurol. 2016.44.

22. Gilhus NE. Myasthenia gravis. N Engl J Med. 2016;375(26):2570-81. https:// doi.org/10.1056/NEJMra1602678.

23. Romi F, Suzuki S, Suzuki N, Petzold A, Plant GT, Gilhus NE. Anti-voltagegated potassium channel Kv1.4 antibodies in myasthenia gravis. J Neurol. 2012;259(7):1312-6. https://doi.org/10.1007/s00415-011-6344-y.

24. Suzuki S, Baba A, Kaida K, Utsugisawa K, Kita Y, Tsugawa J, et al. Cardiac involvements in myasthenia gravis associated with anti-Kv1.4 antibodies. Eur J Neurol. 2014;21(2):223-230. doioi: https://doi.org/10.1111/ene.12234.

25. Becquart O, Lacotte J, Malissart, P, Nadal J, Lesage C, Guillot B, et al. Myasthenia gravis induced by immune checkpoint inhibitors. J Immunother. 2019;42(8):309-312. Doi:CJ10000000000000278.

26. Werner JM, Schweinsberg $V$, Schroeter M, von Reutern B, Malter MP, Schlaak $M$, et al. Successful treatment of myasthenia gravis following PD-1/CTLA-4 combination checkpoint blockade in a patient with metastatic melanoma. Front Oncol. 2019;9:84. https://doi.org/10.3389/fonc.2019.00084.

27. Suzuki S, Ishikawa N, Konoeda F, Seki N, Fukushima S, Takahaski K, et al. Nivolumab-related myasthenia gravis with myositis and myocarditis in Japan. Neurology. 2017:89(11):1127-34. https://doi.org/10.1212/WNL. 0000000000004359 
28. Suzuki S, Utsugisawa K, Yoshikawa H, Motomura M, Matsubara S, Yokoyama $\mathrm{K}$, et al. Autoimmune targets of heart and skeletal muscles in myasthenia gravis. Arch Neurol. 2009;66(11):1334-8. https://doi.org/10.1001/archneurol. 2009.229.

29. Möhn N, Suhs KW, Gingele S, Angela Y, Stangel M, Gutzmer R, et al. Acute progressive neuropathy-myositis-myasthenia-like syndrome associated with immune-checkpoint inhibitor therapy in patients with metastatic melanoma. Melanoma Res. 2019;29(4):435-40. https://doi.org/10.1097/ 0000000000000598

30. Kimura T, Fukushima S, Miyashita A, Aoi J, Jinnin M, Kosaka T, et al. Myasthenic crisis and polymyositis induced by one dose of nivolumab. Cancer Sci. 2016;107(7):1055-8. https://doi.org/10.1111/cas.12961.

31. Kon T, Mori F, Tanji K, Miki Y, Kimura T, Wakabayashi K. Giant cell polymyositis and myocarditis associated with myasthenia gravis and thymoma. Neuropathology. 2013;33(3):281-7. https://doi.org/10.1111/j.14401789.2012.01345.x

32. Chen Q, Huang DS, Zhang LW, Li YQ, Wang HW, Liu HB. Fatal myocarditis and rhabdomyolysis induced by nivolumab during the treatment of type B3 thymoma. Clin Toxicol (Phila). 2018;56(7):667-71. https://doi.org/10.1080/ 15563650.2017.1401079.

33. Fukasawa Y, Sasaki K, Natsume M, Nakashima M, Ota S, Watanabe K, et al. Nivolumab-induced myocarditis concomitant with myasthenia gravis. Case Rep Oncol. 2017;10(3):809-12. https://doi.org/10.1159/000479958.

34. Mahmood SS, Chen CL, Shapnik N, Krishnan U, Singh H, Makker V. Myocarditis with tremelimumab plus durvalumab combination therapy for endometrial cancer: a case report. Gynecol Oncol Rep. 2018;25:74-7. https:// doi.org/10.1016/j.gore.2018.05.014.

\section{Publisher's Note}

Springer Nature remains neutral with regard to jurisdictional claims in published maps and institutional affiliations.

Ready to submit your research? Choose BMC and benefit from:

- fast, convenient online submission

- thorough peer review by experienced researchers in your field

- rapid publication on acceptance

- support for research data, including large and complex data types

- gold Open Access which fosters wider collaboration and increased citations

- maximum visibility for your research: over $100 \mathrm{M}$ website views per year

At $\mathrm{BMC}$, research is always in progress.

Learn more biomedcentral.com/submissions 